OLIVEIRA LS; SILVA TP; FERREIRA APS; PEREIRA AM; FINGER FL. 2015. Efeito do hidroresfriamento na conservação pós-colheita de coentro. Horticultura Brasileira 33: 448-452. http://dx.doi.org/10.1590/S0102-053620150000400007

\title{
Efeito do hidroresfriamento na conservação pós-colheita de coentro
}

\author{
Lucilene S Oliveira; Tania P Silva; Ana PS Ferreira; Ariana M Pereira; Fernando L Finger \\ Universidade Federal de Viçosa (UFV), Viçosa-MG; Brasil, lu_ufv@hotmail.com; taniapiresdasilva@yahoo.com.br; ana.sato.ferreira@ \\ gmail.com; ariana.mota@ufv.br; flfinger@yahoo.com
}

\section{RESUMO}

A redução da taxa transpiratória é essencial para a manutenção da qualidade pós-colheita. A rápida remoção do calor através da técnica de pré-resfriamento proporciona a redução da taxa transpiratória em muitas frutas e hortaliças. As folhas de coentro são suscetíveis a rápida desidratação logo após a colheita. Assim, objetivou-se com este trabalho avaliar a influência do hidroresfriamento na conservação pós-colheita de folhas de coentro 'Português'. Para tanto, folhas de coentro foram arranjadas em maços de $25 \mathrm{~g}$ e submetidas ao armazenamento a $20^{\circ} \mathrm{C}$ e $54 \%$ UR (controle); pré-resfriamento e conservação a $20^{\circ} \mathrm{C}$ e $54 \%$ UR; conservação a $5^{\circ} \mathrm{C}$ e $81 \%$ UR; pré-resfriamento e conservação a $5^{\circ} \mathrm{C}$ e $81 \%$ UR. O pré-resfriamento foi realizado pela imersão dos maços em água gelada a $5^{\circ} \mathrm{C}$ por 10 minutos. Os maços pré-resfriados absorveram água, resultando em acréscimo de $4 \%$ no teor relativo de água (TRA) das folhas. Depois de 72 horas após tratamento hidrotérmico por 10 minutos, o TRA foi reduzido de 89,3 para $88,6 \%$ nos maços armazenados a $20^{\circ} \mathrm{C}$ e não houve redução quando armazenados a $5^{\circ} \mathrm{C}(89,1$ para $90,7 \%)$. Assim, os valores do TRA nesse período permaneceram próximos ao TRA no momento da colheita. $\mathrm{O}$ hidroresfriamento manteve a turgescência das folhas por 3 e 4 dias de conservação dos maços a 20 e a $5^{\circ} \mathrm{C}$, respectivamente. No entanto, mesmo as folhas permanecendo hidratadas, não houve aumento da vida de prateleira devido à ocorrência de degradação da clorofila. O teor de clorofila foi reduzido em 18 e 19,8\% nas folhas pré-resfriadas e conservadas a 20 e $5^{\circ} \mathrm{C}$, respectivamente, ocasionando o descarte dos maços devido ao amarelecimento das folhas. Para as folhas que não foram submetidas ao pré-resfriamento, o teor de clorofila não foi alterado significativamente, sendo o descarte devido ao murchamento das folhas após 48 e $96 \mathrm{~h}$ da colheita para os maços conservados a 20 e $5^{\circ} \mathrm{C}$, respectivamente. Portanto, a conservação do coentro a $5^{\circ} \mathrm{C}$, manteve a qualidade dos maços, mesmo sem uso do resfriamento.

Palavras-chave: Coriandrum sativum, pré-resfriamento, refrigeração.

\begin{abstract}
Effect of hydrocooling in the postharvest shelf life of coriander leaves

The reduction of transpiration rate is necessary to maintain the postharvest quality of fresh harvested fruits or vegetables. The precooling technique provides rapid removal of field heat, reducing transpiration rates in many fruits and vegetables after harvest. Coriander leaves are susceptible to rapid dehydration following harvest. The objective of this study was to evaluate the influence of hydrocooling in postharvest shelf life of coriander leaves (Coriandrum sativum) cv. Português. Bundled coriander leaves (25 g) were subjected to storage at $20^{\circ} \mathrm{C}$ and $54 \% \mathrm{RH}$ (control); pre-cooling and storage at $20^{\circ} \mathrm{C}$ and $54 \% \mathrm{RH}$; storage at $5^{\circ} \mathrm{C}$ and $81 \% \mathrm{RH}$; pre-cooling and storage at $5^{\circ} \mathrm{C}$ and $81 \% \mathrm{RH}$. Pre-cooling was performed by submerging bundles into cold water $\left(5^{\circ} \mathrm{C}\right)$ for 10 minutes. Pre-cooled bundles absorbed water, resulting in a $4 \%$ increase in relative water content (RWC) of the leaves. Seventy-two hours after pre-cooling during 10 minutes, the RWC declined from $89.3 \%$ to $88.6 \%$ in bundles stored at $20^{\circ} \mathrm{C}$. For those coriander bundles stored at $5^{\circ} \mathrm{C}(89.1 \%$ to $90.7 \%)$ there was no reduction in RWC. Hydrocooling maintained leaf turgidity for 3 and 4 days storage at $20^{\circ} \mathrm{C}$ and $5^{\circ} \mathrm{C}$ respectively. Despite leaves remaining hydrated, no increase in shelf life occurred because of chlorophyll degradation. Chlorophyll content of pre-cooled leaves was reduced by $18 \%\left(20^{\circ} \mathrm{C}\right.$ storage) and $19.8 \%\left(5^{\circ} \mathrm{C}\right.$ storage $)$. These bundles had to be discarded because of leaf yellowing. Leaves that were not subject to pre-cooling did not exhibit a significant change in chlorophyll content. These leaves wilted $48 \mathrm{~h}\left(20^{\circ} \mathrm{C}\right.$ storage $)$ and $96 \mathrm{~h}\left(5^{\circ} \mathrm{C}\right.$ storage $)$ after harvest and were discarded. Storage of coriander at $5^{\circ} \mathrm{C}$ maintained quality regardless of whether bundles were pre-cooled or not.
\end{abstract}

Keywords: Coriandrum sativum, pre-cooling, refrigeration.

(Recebido para publicação em 10 de dezembro de 2014; aceito em 12 de maio de 2015) (Received on December 10, 2014; accepted on May 12, 2015)

$\mathrm{O}$ coentro (Coriandrum sativum) é uma hortaliça folhosa que possui vida de prateleira curta, sendo consumido na forma de produto fresco ou como condimento em diversos pratos culinários. As folhas de coentro são suscetíveis à rápida perda de água após a colheita, tornando-as inviáveis para a comerciali- zação. A perda de água acarreta diversas mudanças na aparência, metabolismo e composição de hortaliças (Kays \& Paull, 2004), com consequentes alterações na coloração, qualidade nutricional (Wills et al., 2007) e vitalidade. Diante deste contexto, recomenda-se o uso de método que retarde os processos de deterioração, incluindo técnicas de pré-resfriamento antes do armazenamento refrigerado.

$\mathrm{O}$ pré-resfriamento promove a manutenção da qualidade de muitas frutas e hortaliças, por retirar rapidamente o calor de campo antes de serem comercializadas, armazenadas ou processadas (Becker \& Fricke, 2002). A aplicação 
desta técnica antes da refrigeração contribui para a redução da temperatura do produto oriundo do calor de campo e também do calor vital, o que ocorreria de forma lenta em uma câmara fria. Resultando assim, no controle mais rápido das taxas de temperatura e transpiração. As técnicas para remover o calor de campo de frutas e hortaliças recém-colhidas podem reduzir a atividade microbiana, as taxas respiratórias, transpiratórias, a senescência, assim como a produção de etileno (Kalbasi-Ashtari, 2004).

O hidroresfriamento, resfriamento com água gelada, tem se mostrado eficiente no aumento da vida de prateleira de muitas frutas e hortaliças, como lichia, pêssego, aspargo, milho doce, cereja, alface e salsa (Becker \& Fricke, 2002; Alique et al., 2006; Alvarez et al., 2007; del Aguila et al., 2009). Em frutos de lichia, o tratamento hidrotérmico promove a manutenção do brilho e retardamento do escurecimento (Del Aguila et al., 2009). Em folhas de salsa, a rápida redução da temperatura retarda a perda de matéria fresca e a perda de água (Alvarez et al., 2007). O hidroresfriamento possui alta eficiência devido à alta condutividade térmica da água, além do contato uniforme entre a água e a superfície do produto que promove rápida redução da temperatura (Tsang \& Furutani, 2006). Entre as vantagens desta técnica tem-se a não desidratação do produto durante o processo, além de poder ocorrer a absorção de água pelo produto (Fricke, 2006).

Apesar de diversos trabalhos comprovarem a eficiência desta técnica, não há relatos sobre o efeito em coentro, uma hortaliça altamente perecível. Portanto, este trabalho teve por objetivo avaliar a influência do hidroresfriamento e do armazenamento refrigerado na conservação pós-colheita de folhas de coentro cultivar 'Português'.

\section{MATERIAL E MÉTODOS}

Foram utilizadas folhas de coentro, cultivar Português, obtidas de plantas cultivadas no campo experimental da Universidade Federal de Viçosa (2045'14'S, 42 52 '55'O, $650 \mathrm{~m}$ de altitude). As folhas de coentro foram colhidas aos 45 dias após a semeadura, no período da manhã e imediatamente transportadas em caixa de isopor ao laboratório.

As folhas foram selecionadas, retirando-se aquelas deterioradas e murchas. Em seguida, foram arranjadas em maços de $20 \mathrm{~cm}$ de comprimento e 25 g e submetidas à conservação a $20^{\circ} \mathrm{C}$ e $54 \%$ UR (controle); pré-resfriamento e conservação a $20^{\circ} \mathrm{C}$ e $54 \%$ UR; conservação a $5^{\circ} \mathrm{C}$ e $81 \%$ UR; pré-resfriamento e conservação a $5^{\circ} \mathrm{C}$ e $81 \%$ UR. O pré-resfriamento foi realizado pela imersão total dos maços em água gelada a $5^{\circ} \mathrm{C}$ por 10 minutos. Os maços foram conservados, até o fim da vida de prateleira, a 5 ou $20^{\circ} \mathrm{C}$ em caixas de colheita $(25 \times 48 \times 15 \mathrm{~cm})$ envoltas por plástico de polietileno perfurado, com furos de 11 $\mathrm{mm}$, espaçados em $10 \mathrm{~cm}$.

Para a definição do tempo de pré-resfriamento foram realizados testes com maços de coentro submetidos ao pré-resfriamento com a mistura de gelo moído e água $(1: 3 \mathrm{v} / \mathrm{v})$ a $5^{\circ} \mathrm{C}$. Em seguida determinou-se a temperatura dos maços em intervalos de 5 minutos, com uso de um termômetro infravermelho. $\mathrm{O}$ tempo ideal de pré-resfriamento estabelecido foi quando ocorreu a estabilização da temperatura dos maços.

Durante a conservação, a avaliação dos teores de clorofila e perda de massa fresca foi realizada, inicialmente, a cada $6 \mathrm{~h}$ até $48 \mathrm{~h}$ após o tratamento e depois em intervalo de $24 \mathrm{~h}$. A perda de massa fresca foi estimada em relação à massa da matéria fresca inicial dos maços, antes dos tratamentos, e expressa em porcentagem. O teor de clorofila foi avaliado utilizando o medidor portátil SPAD-502 (Minolta, Japan). Para o teor relativo de água (TRA) foram feitas avaliações, logo após a colheita e em intervalos de $24 \mathrm{~h}$ após a realização dos tratamentos. As mensurações foram feitas conforme descrito por Álvares et al. (2007) utilizando 11 discos de 0,8 $\mathrm{cm}$ das folhas.

$\mathrm{O}$ experimento foi conduzido em delineamento inteiramente casualizado, com quatro repetições. A unidade experimental foi constituída de um maço de folhas. Os dados foram submetidos à análise de regressão, sendo o modelo escolhido de acordo com o coeficiente de determinação e o fenômeno biológico.

\section{RESULTADOS E DISCUSSÃO}

Quando as folhas de coentro foram imersas na mistura de gelo e água a $5^{\circ} \mathrm{C}$ houve rápida queda da temperatura. $\mathrm{Em}$ 10 minutos de imersão a temperatura dos maços foi reduzida em 65,8\% (Figura 1). Após este tempo, houve estabilização da temperatura, indicando que o período apropriado de pré-resfriamento, deve ser a partir de 10 minutos para o hidroresfriamento nas condições desse experimento. Em geral, os tempos típicos de resfriamento com água gelada variam de 10 minutos a 1 hora, dependendo da dimensão e da temperatura inicial do produto (Cortez et al., 2002).

A perda de massa fresca para o controle ocorreu de forma rápida, acarretando murchamento das folhas e descarte dos maços, $48 \mathrm{~h}$ após o início da conservação a $20^{\circ} \mathrm{C}$ (Figura 2). A temperatura e a umidade relativa do ar são fatores determinantes no controle da perda de água em frutas e hortaliças após a colheita (Finger \& Vieira, 1997) e a redução da temperatura aumenta a conservação por diminuir a diferença de pressão de vapor entre o interior da planta e o meio, reduzindo a perda de água (Wills et al., 2007). Na conservação do coentro, independente do uso ou não do pré-resfriamento à temperatura de $5^{\circ} \mathrm{C} \mathrm{e}$ umidade relativa de $81 \%$, houve retardamento da perda de massa da matéria fresca, ao longo de toda a vida de prateleira, quando comparado a $20^{\circ} \mathrm{C}$. Na ausência de pré-resfriamento, a perda de massa fresca foi de apenas $11,27 \%$ para os maços armazenados a $5^{\circ} \mathrm{C}$, enquanto que para os maços conservados a $20^{\circ} \mathrm{C}$ a perda foi superior a $20 \%$ após $48 \mathrm{~h}$ de armazenamento, resultando em fim da vida de prateleira do controle (Figura 2).

Em maços de coentro conservados a $20^{\circ} \mathrm{C}$, a taxa da perda de massa por hora, foi de $0,64 \%$ e $0,49 \%$, nos maços sem e com hidroresfriamento, respectivamente (Figura 2). Para os maços conservados a $5^{\circ} \mathrm{C}$ a perda de massa foi de $0,22 \%$ e $0,37 \%$ por hora para o tratamento sem hidroresfriamento e hidroresfriado, respectivamente (Figura 2). Apesar de os maços a $5^{\circ} \mathrm{C}$ sem pré-resfriamento 
terem menor perda de massa fresca por hora que os pré-resfriados e mantidos a $5^{\circ} \mathrm{C}$. Visualmente este último tratamento proporcionou maior tempo de turgescência das folhas. Esse fato pode ser explicado pela retenção inicial de água

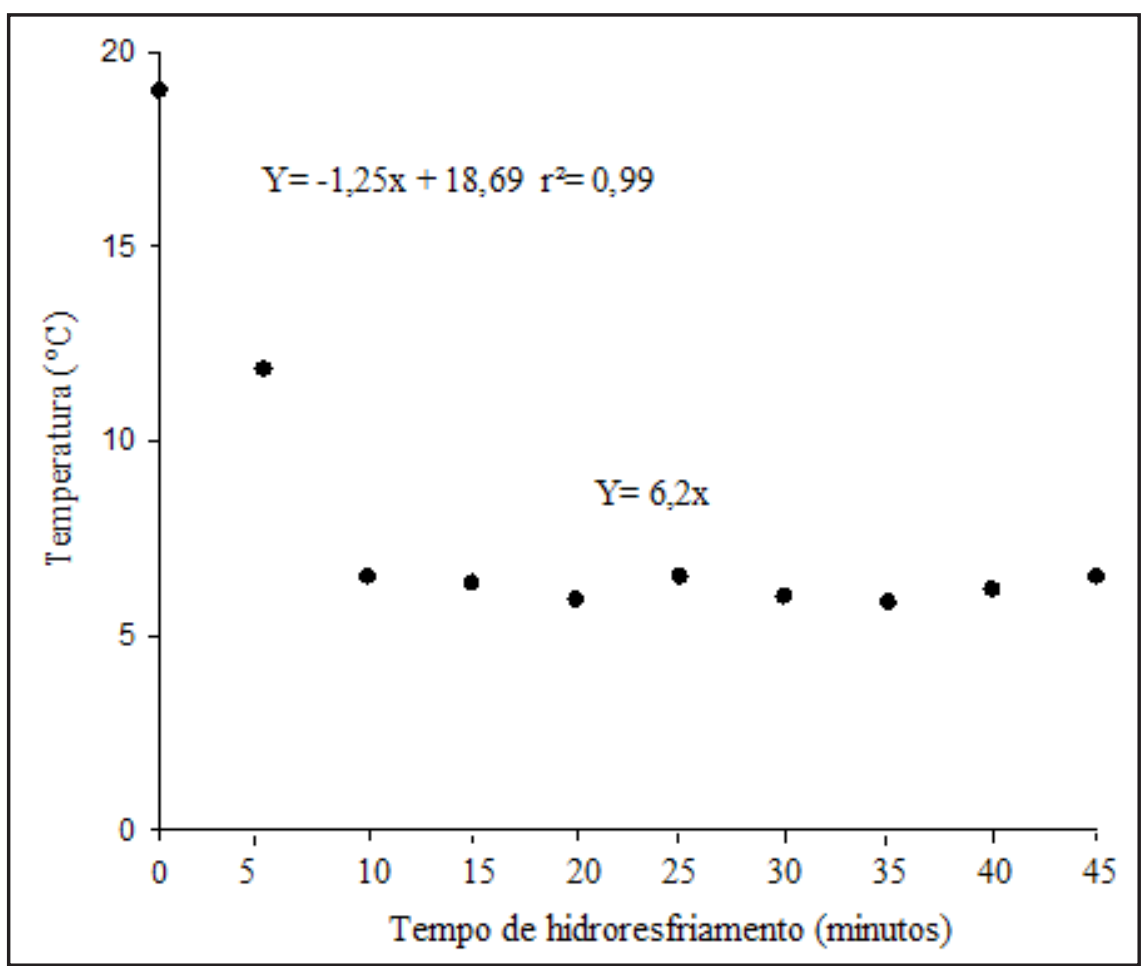

Figura 1. Influência do tempo de hidroresfriamento na temperatura em maços de coentro resfriados com mistura de água e gelo a $5^{\circ} \mathrm{C}$ (influence of hydrocooling time on the temperature of coriander bundles cooled with a $5^{\circ} \mathrm{C}$ water and ice mixture). Viçosa, UFV, 2011.

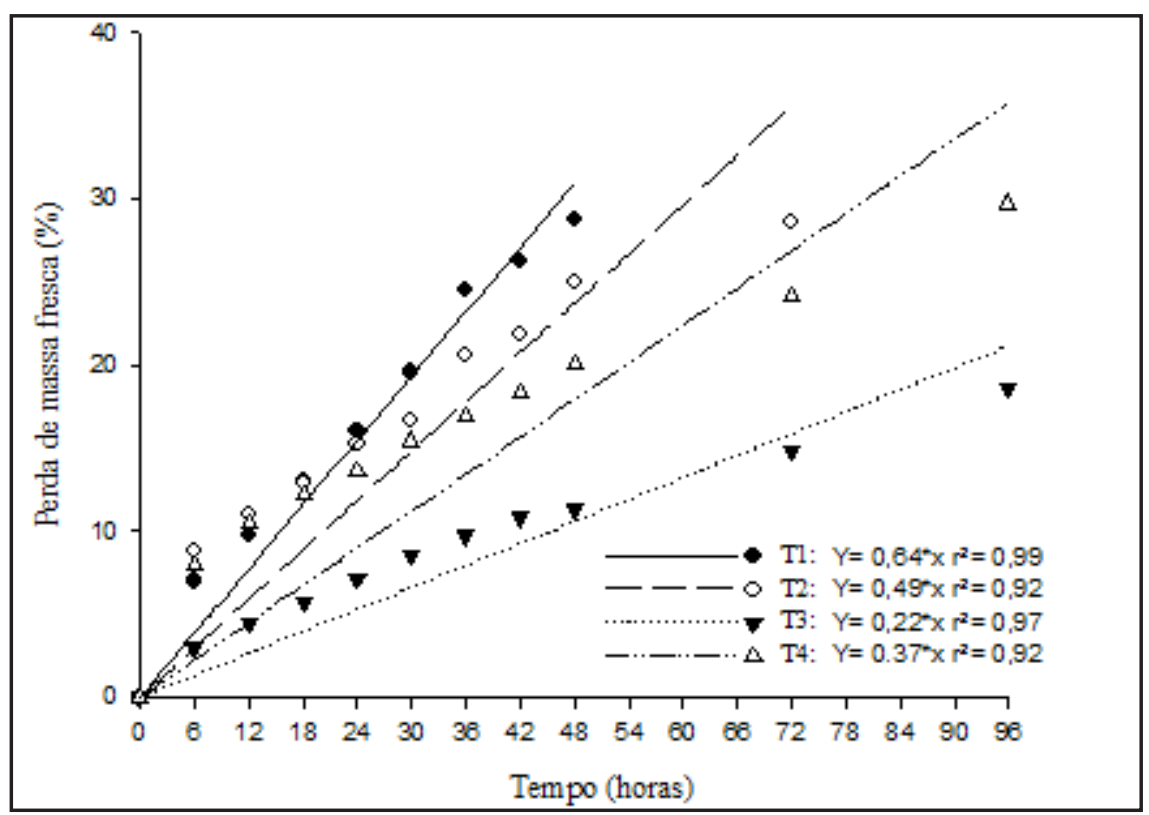

Figura 2. Perda de massa acumulada (\%) em maços de coentro em função do tempo de armazenamento a $20^{\circ} \mathrm{C}$, sem e com hidroresfriamento (T1 e T2, respectivamente), e armazenados a $5^{\circ} \mathrm{C}$ sem e com hidroresfriamento (T3 e T4, respectivamente), * significativo a $1 \%$ de probabilidade pelo teste $\mathrm{F}$ \{cumulative mass loss (\%) of coriander bundles depending on storage time at $20^{\circ} \mathrm{C}$ with and without pre-cooling (T1 and $\mathrm{T} 2$, respectively) and stored at $5^{\circ} \mathrm{C}$ with and without pre-cooling (T3 and $\mathrm{T} 4$, respectively), * significant at $1 \%$ probability by F test\}. Viçosa, UFV, 2011. nas folhas pela aplicação do hidroresfriamento, levando à superestimação da perda de massa. Diferentemente, o uso do pré-resfriamento com gelo picado em brócolis retardou a perda de massa em 34,6\% nas primeiras $24 \mathrm{~h}$ de armazenamento a $5^{\circ} \mathrm{C}$ (Galvão et al., 2008), enquanto nas folhas de coentro hidroresfriadas a perda de massas no mesmo período foi $47,7 \%$ superior àquelas não resfriadas. A perda de massa fresca em vegetais pode ser atribuída à evaporação da água retida após a lavagem; devida à respiração que consiste na oxidação de carboidratos em dióxido de carbono e água; e, devida à desidratação, que é a perda de água resultante da diferença de pressão de vapor d'agua entre o interior do vegetal e o meio circundante (Moreira et al., 2006). Em folhas de coentro, a maior perda de massa fresca foi relacionada à água retida para as folhas pré-resfriadas e à desidratação, confirmados pelos valores verificados para TRA.

Independente do fato se os maços foram armazenados a 20 ou a $5^{\circ} \mathrm{C}$, sem hidroresfriamento, não ocorreram alterações significativas no teor de clorofila durante o armazenamento. Entretanto, nos maços pré-resfriados, houve queda relevante no nível de clorofila 72 e 96 $\mathrm{h}$ após o tratamento das folhas, armazenadas a 20 e a $5^{\circ} \mathrm{C}$, respectivamente (Figura 3). A redução do teor de clorofila foi de $18 \%$ nos maços pré-resfriados e conservados a $20^{\circ} \mathrm{C}$, após $72 \mathrm{~h}$, e de $19,8 \%$ nos pré-resfriados e mantidos a $5^{\circ} \mathrm{C}$, após $96 \mathrm{~h}$, ocasionando o descarte dos maços devido ao amarelecimento das folhas (Figura 3). Portanto, sugere-se que o hidroresfriamento em folhas de coentro estimulou a degradação de clorofila. Em contrapartida, Alvarez et al. (2007) constataram que o uso do pré-resfriamento seguido do armazenamento a $5^{\circ} \mathrm{C}$ em folhas de salsa (Petroselinum crispum), hortaliça da mesma família do coentro, não estimulou degradação de clorofila. Em folhas de coentro, por sua vez, ocorreu seu amarelecimento, o que pode estar relacionado à intolerância do coentro à redução imediata da temperatura das folhas, resultado do rápido resfriamento imposto pelo hidroresfriamento. Segundo Heaton et al. (1996), a degradação de clorofila 


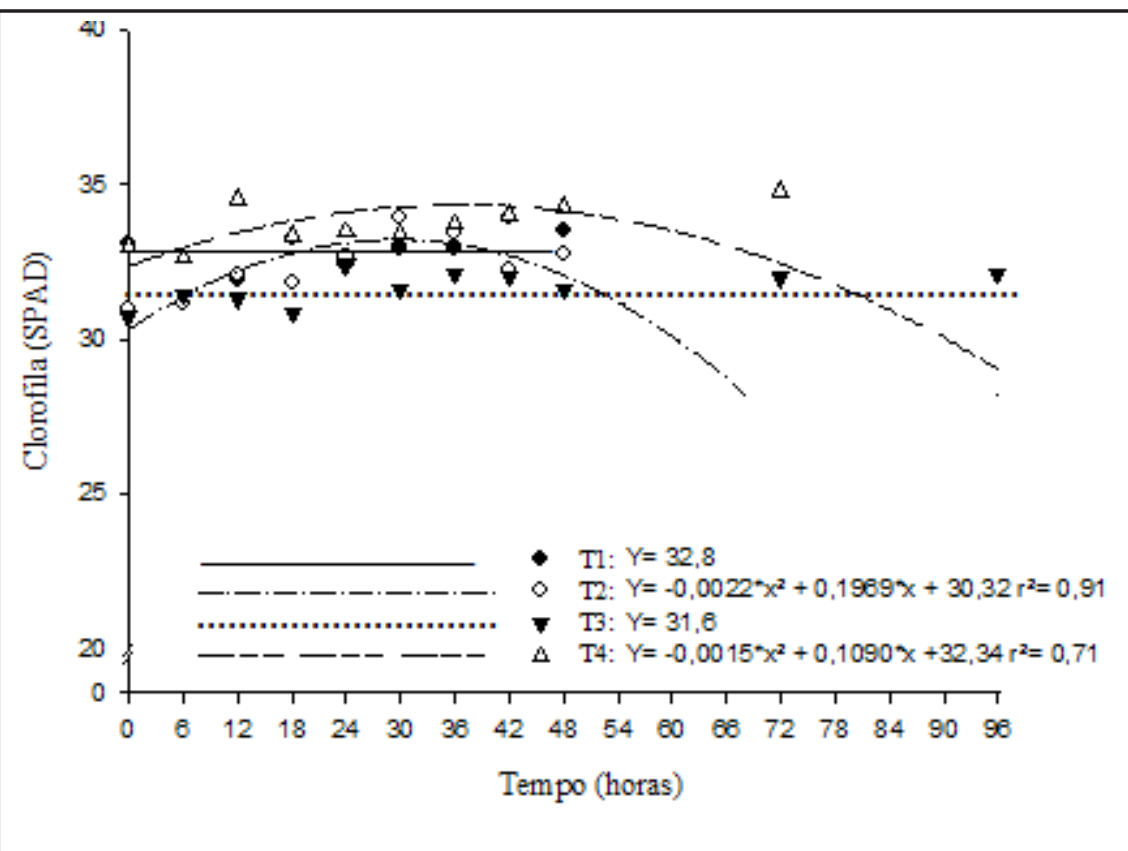

Figura 3. Teor de clorofila (unidades SPAD) de folhas de coentro em função do tempo de armazenamento, a $20^{\circ} \mathrm{C}$ sem e com hidroresfriamento (T1 e T2, respectivamente), e armazenadas a $5^{\circ} \mathrm{C}$ sem e com hidroresfriamento (T3 e T4, respectivamente), * significativo a $1 \%$ de probabilidade pelo teste $\mathrm{F}$ \{chlorophyll content (SPAD units) of coriander leaves depending on storage time at $20^{\circ} \mathrm{C}$ with and without pre-cooling ( $\mathrm{T} 1$ and $\mathrm{T} 2$, respectively) and stored at $5^{\circ} \mathrm{C}$ with and without pre-cooling (T3 and $\mathrm{T} 4$, respectively ), *significant at $1 \%$ probability by $\mathrm{F}$ test $\}$. Viçosa, UFV, 2011.

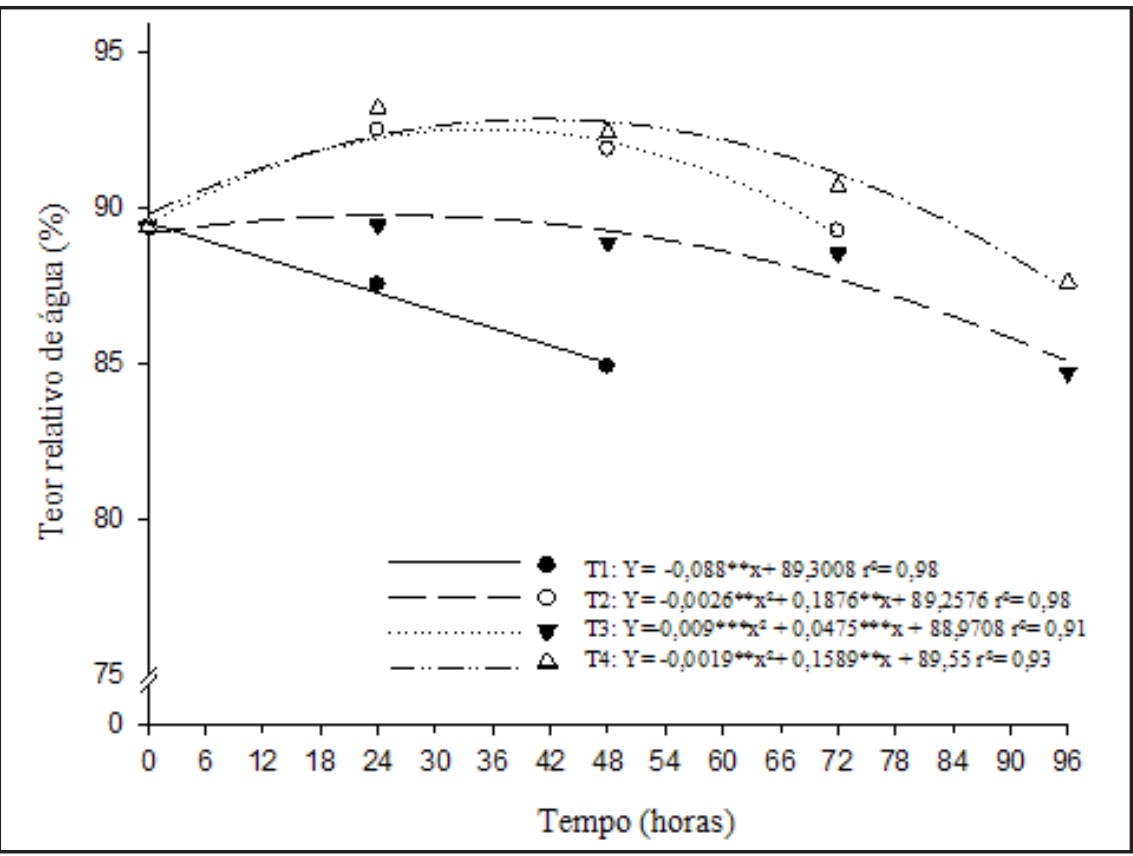

Figura 4. Teor relativo de água (\%) em folhas de coentro em função do tempo armazenadas a $20^{\circ} \mathrm{C}$ sem e com hidroresfriamento ( $\mathrm{T} 1 \mathrm{e} \mathrm{T} 2$, respectivamente), e armazenadas a $5^{\circ} \mathrm{C}$ sem e com hidroresfriamento (T3 e T4, respectivamente), ${ }^{* *}$ significativo a $5 \%$ de probabilidade. $* * *$ significativo a $10 \%$ de probabilidade relative water content $(\%)$ on coriander leaves depending on time of storage at $20^{\circ} \mathrm{C}$ with and without pre-cooling (T1 and T2, respectively) and stored at $5{ }^{\circ} \mathrm{C}$ with and without pre-cooling (T3 and T4, respectively), ${ }^{* *}$ significant at $5 \%$, *** significant at 10\% . Viçosa, UFV, 2011. em tecidos senescentes é iniciada por diversos fatores incluindo alterações térmicas, o que pode ter ocorrido em coentro submetido ao pré-resfriamento.

Nas folhas sem pré-resfriamento e conservadas a $20^{\circ} \mathrm{C}$ houve rápida perda de água, sendo que no segundo dia após a colheita, com teor relativo de água de $84,9 \%$, as folhas apresentaram-se totalmente murchas (Figura 4). A conservação do coentro em baixa temperatura retardou a perda de água devido à redução do gradiente de potencial hídrico entre $o$ ambiente e as folhas, o que desfavorece o processo de transpiração. Nas folhas não hidroresfriadas e conservadas a $5^{\circ} \mathrm{C}$ a perda de massa foi menor, de modo que apresentaram-se murchas $96 \mathrm{~h}$ após o início do armazenamento, quando o teor relativo de água estava próximo ao controle $(84,7 \%)$ em $48 \mathrm{~h}$, quando estes foram descartados (Figura 4).

Para os maços pré-resfriados houve acréscimo de aproximadamente $4 \%$ no teor relativo de água das folhas (Figura 4). Assim, o hidroresfriamento permitiu a manutenção da turgescência durante os 3 e 4 dias de longevidade dos maços conservados a 20 e a $5^{\circ} \mathrm{C}$, respectivamente. $\mathrm{O}$ uso do pré-resfriamento, com água gelada, retardou a perda de água possivelmente por permitir a absorção da mesma durante a imersão e também por diminuir o gradiente de pressão de vapor entre o produto e o meio circundante. Todavia, o hidroresfriamento acelerou o processo de degradação de clorofila. Portanto, o tratamento hidrotérmico não foi ágil na conservação do coentro. Recomenda-se portanto a refrigeração a $5^{\circ} \mathrm{C}$ apenas, sem pré-resfriamento.

\section{AGRADECIMENTOS}

Ao CNPq pelo apoio financeiro.

\section{REFERÊNCIAS}

ALIQUE R; MARTÍNEZ MA; ALONSO J. 2006. Metabolic response to two hydrocooling temperatures in sweet cherries cv Lapins and cv Sunburst. Journal Science Food Agriculture 86: 1847-1854. 
ÁLVARES VS; FINGER FL; SANTOS RCA; SILVA JR; CASALI VWD. 2007. Effect of pre-cooling on the postharvest of parsley leaves. Journal of Food, Agriculture \& Environment 5: 31-34.

BECKER BR; FRICKE BA. 2002. Hydrocooling time estimation methods. 2002. International Communications in Heat and Mass Transfer 29: $165-174$.

CORTEZ LAB; VIGNEAULT C; CASTRO LR. 2002. Método de resfriamento rápido por água gelada. In: CORTEZ LAB; HONÓRIO SL; MORETTI CL (eds). Resfriamento de frutas e hortaliças. Brasília: Embrapa Hortaliças. p. 274-281.

DEL AGUILA JS; HOFMAN P; CAMPBELL T; MARQUES JR; HEIFFIG-DELAGUILA LS; KLUGE RA. 2009. Hydrocooling of 'b3' lychee fruit maintained in cold storage.
Ciência Rural 39: 2373-2379.

FINGER FL; VIEIRA G. 1997. Controle da perda pós-colheita de água em produtos hortícolas. Viçosa: UFV. 29p.

FRICKE BA. 2006. Precooling of fruits and vegetables. ASHRAE Journal 48: 20-28.

GALVÃO HL; FINGER FL; PUIATTI M; CORRÊA PC; OLIVEIRA LS. 2008. Efeito do pré-resfriamento e do filme de PVC sobre a conservação pós-colheita de brócolis. Revista Brasileira de Armazenamento 33: 101-106.

HEATON JW; LENCKI RW; MARANGONI AG. 1996. Kinetic model for chlorophyll degradation in green tissue. Journal of Agricultural Food Chemistry 44: 399-402.

KALBASI-ASHTARI A. 2004. Effects of postharvest pre-cooling processes and cyclical heat treatment on the physico-chemical properties of "Red Haven Peaches" and "Shahmavch
Pears" during cold storage. Agricultural Engineering International 6: 1-17.

KAYS SJ; PAULL RE. 2004. Postharvest Biology. Georgia: Exon Press. 568p.

MOREIRA MDR; PONCEB AG; VALLEA CED, ANSORENAB R; ROURAB SI. 2006. Effects of abusive temperatures on the postharvest quality of lettuce leaves: ascorbic acid loss and microbial growth. Journal of Applied Horticulture 8: 109-113.

TSANG M; FURUTANI S. 2006. A low cost hydrocooling unit for horticultural commodities. Journal Hawaii Pacific Agriculture 14: 1.

WILLS R; McGLASSOM B; GRAHAM D; JOYCE D. 2007. Postharvest: an introduction to the physiology and handling of fruit, vegetables and ornamentals. New York: $\mathrm{CAB}$ International. 252p. 